\title{
Relation between Minimum Inhibitory Concentration and Chemical Structure of Heterocyclic Organic Compounds against Mycobacterium
}

\author{
Vida Sedighi, Masoomeh Shirzad*, Safora Hariri, Pegah Adelvand, Soroush Sardari* \\ Drug Design and Bioinformatics Unit, Medical Biotechnology Department, Biotechnology Research Center, Iran \\ Received Date: July 18, 2018; Published Date: October 01, 2018 \\ *Corresponding author: Soroush Sardari, Drug Design and Bioinformatics Unit, Medical Biotechnology Department, Biotechnology Research \\ Center, Pasteur Institute of Iran, Tehran, Fax: +98 (21) 6648-0780; Email: ssardari@hotmail.com \\ Masoomeh Shirzad, Drug Design and Bioinformatics Unit, Medical Biotechnology Department, Biotechnology Research Center, Pasteur Institute of \\ Iran, Tehran, Tel: +989122632484; Email: masishirzad@hotmail.com
}

Abstract

This study aimed to study different derivatives of heterocyclic organic compounds and related antibacterial activities of these compounds which were evaluated against Mycobacterium tuberculosis. This review represents an overview of minimum inhibitory concentration (MIC) of these compounds to find a meaningful relationship between chemical structure of the compounds and the related MIC values. The chemical structures of these compounds have been classified into 11 groups. Among the 100 evaluated compounds in this study, a non-fused heterocyclic compound and fused heterocyclic compound were found to be the most active compound with MIC of 0.06 and $0.003 \mu \mathrm{g} / \mathrm{ml}$ against Mycobacterium, respectively. Some chemical properties impact antibacterial activities of these compounds, which depend on the delocalized electrons in the structure of the compounds and the presence of electronegative element such as nitrogen or oxygen in the rings of the compounds.

Keywords: Chemical structure; Minimum inhibitory concentration (MIC); Mycobacterium; Delocalized electrons; Heterocyclic organic compounds.

\section{Introduction}

People with active tuberculosis have to take several medications for months. Based on the World Health Organization (WHO) estimation, two millions of people die from tuberculosis (TB) each year. During the treatment of TB, the patients receive chemotherapy for 6 months to cure and also promote side effects $[1,2]$. Isoniazid, streptomycin, rifampin, and pyrazinamide have been used as antituberculosis drugs [3]. On the other hand, some tuberculosis patients do not respond to medication at the beginning of the treatment. If the right drugs chose, the treatment time decrease and subsequently the drug-resistant strains moderate or even eliminate. The clinical trials data for isoniazid and rifampin showed that these drugs were effective and also showed that tolerability for a three month period was sufficient to prevent TB [4]. The results of clinical trials for streptomycin and pyrazinamide showed same results [5].

One of the most important mortality in the developing countries such as in Bangladesh and Africa is TB. Although it is found that mortality decrease by chemotherapy which is insufficient especially in the developing countries [6]. Of course, WHO has estimated that $7 \%$ of death in the developing countries occur in adults by single source [7]. In 2007, about 9.2 million people died and also Bangladesh was ranked as one of the highestrated TB countries $[8,9]$. Therefore, it is essential to synthesize new chemical compounds with improved effective properties to treat TB. This study aimed to find a significant relationship between the minimum inhibitory concentration (MIC) values and the related chemical structures of heterocyclic organic compounds against Mycobacterium tuberculosis. The MIC value is defined as the lowest drug concentration with no visible growth after incubation.

\section{Organic compounds}

Table1: Classification of efficiencies based on the related MIC values.

\begin{tabular}{|c|c|}
\hline Mean MIC value $(\boldsymbol{\mu g} / \mathbf{m l})$ & Efficiency \\
\hline$<1$ & Very potent \\
\hline $01-O c t$ & Potent \\
\hline $10-100$ & Medium \\
\hline$>100$ & Weak \\
\hline
\end{tabular}

To compare the potential effect of chemical structures on growth of Mycobacterium tuberculosis, four types including of very potent, potent, medium and weak in terms of mean MIC values have been shown in Table 1 [10]. The organic compounds could be classified based on their scaffolds into 11 groups mentioned in Table 2. Some of the significant moieties of the mentioned 


\section{Novel Approaches in Drug Designing \& Development}

classifications of organic compounds and related MIC values compounds and related MIC values will help the researchers to have been summarized in Table 3. Subsequently the chemical anticipate the MIC range before experiment.

Table 2: Classification of organic compounds into 11 main groups and their subgroups.

\begin{tabular}{|c|c|c|c|}
\hline Main group & Subgroup & Number of subgroups & Groups \\
\hline Chain compounds & - & - & 1 \\
\hline Compounds with one 5-membered ring & - & - & 2 \\
\hline Compounds with one 6-membered ring & - & - & 3 \\
\hline \multirow[b]{2}{*}{ T Compounds with two non-fused rings } & Compounds with 5 and 6-membered non-fused rings & \multirow[b]{2}{*}{2} & \\
\hline & Compounds with two 6-membered non-fused rings & & 4 \\
\hline \multirow{3}{*}{ Compounds with two fused rings } & Compounds with two 5-membered fused rings & \multirow[b]{3}{*}{3} & \multirow[b]{3}{*}{5} \\
\hline & Compounds with 5 and 6-membered fused rings & & \\
\hline & Compounds with two 6-membered fused rings & & \\
\hline \multirow{2}{*}{ Compounds with three non-fused rings } & Compounds with three 5 and 6-membered non-fused rings & \multirow{2}{*}{2} & \multirow{2}{*}{6} \\
\hline & Compounds with three 6-membered non-fused rings & & \\
\hline \multirow{2}{*}{ Compounds with three fused rings } & $\begin{array}{l}\text { Compounds with two } 5 \text { and 6-membered fused and one } \\
\text { 6-membered non-fused rings }\end{array}$ & \multirow[b]{2}{*}{2} & \multirow[b]{2}{*}{7} \\
\hline & $\begin{array}{c}\text { Compounds with two 6-membered fused and one 6-membered } \\
\text { non-fused rings }\end{array}$ & & \\
\hline \multirow{5}{*}{ Compounds with four rings } & Compounds with four non-fused rings & \multirow{5}{*}{5} & \multirow{5}{*}{8} \\
\hline & Compounds with two non-fused and two fused rings & & \\
\hline & Compounds with two set of two fused rings & & \\
\hline & Compounds with three fused and one non-fused rings & & \\
\hline & Compounds with four fused rings & & \\
\hline \multirow{2}{*}{ Compounds with five rings } & Compounds with four fused and one non-fused rings & \multirow[b]{2}{*}{2} & \multirow[b]{2}{*}{9} \\
\hline & Compounds with three fused and one non-fused rings & & \\
\hline Compounds with six rings & - & - & 10 \\
\hline Compounds with seven rings & - & - & 11 \\
\hline
\end{tabular}

Table 3: Some important moieties in the chemical structure of 11 groups of heterocyclic organic compounds for classification of these compounds, related MIC values and example of the chemical compounds.

\begin{tabular}{|c|c|c|c|}
\hline Class & Significant moiety & $\begin{array}{c}\text { Example } \\
\text { Typical MIC } \\
(\mu \mathrm{g} / \mathrm{ml})\end{array}$ & \multicolumn{1}{c|}{ Reference } \\
\hline $\begin{array}{c}\text { Substituted acetamide } \\
\text { (Chain Compounds) }\end{array}$ & - CONRR' $^{\prime}$ & & \\
\\
\hline
\end{tabular}




\begin{tabular}{|c|c|c|c|c|}
\hline Substituted cinnamide (one 6-membered ring) & $\mathrm{C}_{6} \mathrm{H}_{5} \mathrm{CH}=\mathrm{CHCONHR}$ & 5 & 208 & [17] \\
\hline Substituted acrylamide (two non-fused rings) & CHR $=$ CHCONHR' & 6 & 42 & [17] \\
\hline $\begin{array}{l}\text { Substituted Benzenesulfonamide (two non-fused } \\
\text { rings) }\end{array}$ & $\mathrm{C}_{6} \mathrm{H}_{5} \mathrm{SO}_{2} \mathrm{NHR}$ & 8 & 32 & [23] \\
\hline Substituted Imidazole (two non-fused rings) & & 9 & 42 & [29] \\
\hline $\begin{array}{l}\text { Substituted Hydrazonamide (two non-fused 6-mem- } \\
\text { bered rings) }\end{array}$ & $\mathrm{R}^{\prime} \mathrm{COHNN}=\mathrm{CHR}$ & 11 & 20 & [32] \\
\hline Substituted Pyrazole (four non-fused 5 and & $\mathrm{RR}^{\prime} \mathrm{R}^{\prime \prime}-\mathrm{C}_{3} \mathrm{HN}_{2}$ & 17 & 0.06 & [49] \\
\hline $\begin{array}{l}\text { Substituted Isonicotinamide (three non-fused 6- mem- } \\
\text { bered rings) }\end{array}$ & $\mathrm{C}_{5} \mathrm{H}_{4} \mathrm{NCONRR}^{\prime}$ & 16 & 7.6 & [43] \\
\hline
\end{tabular}

\section{The Chain Compounds}

Some of chemical structures of the organic compounds illustrate in Figure 1 so that for the 1 containing amide group and $\mathrm{OH}$ group, a weak MIC value has been reported $[11,12]$. However, secondary amine group $\left(\mathrm{R}_{2}-\mathrm{NH}\right)$ in the structure should be shown a better MIC value compared to the other chemical compounds of this group [13]. Additionally, in this group with more $\mathrm{OH}$ groups than amide group, should make the MIC value to be increased to provide weaker antibacterial effects compared to the other chemical compounds of this group. By substitution of a tertiary amine group (R3-N), a better MIC value has been shown 
compared with the substitution of the $\mathrm{OH}$ group. In this group, value for 28 samples of this group has been obtained $200.50 \mu \mathrm{g} /$ chain structures present a weak MIC value [14]. The mean MIC $\mathrm{ml}$ in the weak MIC range.<smiles>O=C(CO)N(CCO)CCO</smiles>

1<smiles>CC(=O)NCCSC(=O)/C=C/c1ccccc1</smiles><smiles>[2H]c1ccc(C(=O)N2CCCC2)o1</smiles>

2<smiles>[R]C1OC(C(O)CO)C(O)C1O</smiles>

as<smiles>CC(=O)NCCNC(=O)/C=C/c1ccccc1</smiles>

Figure 1: The structures of chemical compounds belonging to groups 1,2 and 3.

\section{The Compounds with One 5-Membered Ring}

In the 2 due to the presence of delocalized electrons, amide group and also heteroatom in cyclic organic compounds shows a more intense MIC value compared with the 3 which does not have delocalized electrons in the structure $[15,16]$. The mean MIC value for 23 samples of this group has been obtained $0.09 \mu \mathrm{g} / \mathrm{ml}$ which was considered as a very potent MIC value.

\section{The Compounds with One 6-Membered Ring}

In the 4 and 5 consisting one phenyl and one amide group and also presence of sulfur (S) atom in the structure which were considered as a weak MIC value [17-22]. The mean MIC value for this group has been obtained $208.9 \mu \mathrm{g} / \mathrm{ml}$ which was considered as a weak MIC value.

\section{The compounds with Two Non-Fused Rings}

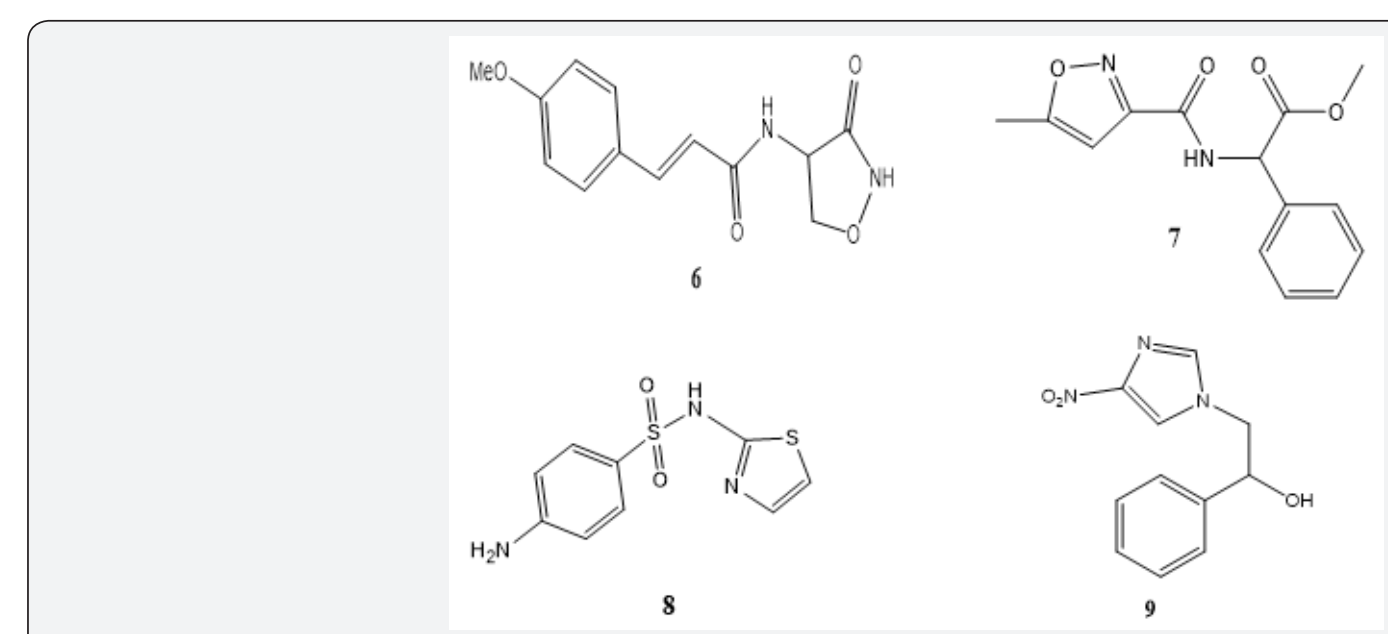

Figure 2: The chemical structures of non-fused compounds belonging to group 4.1.

The compounds with 5 and 6-membered Non-Fused Rings: The compounds of this group containing phenyl group with 5 and 6-membered rings have been presented in Figure 2 so that for 6 weak MIC value related to lack of delocalized electrons in the whole molecule [17]. However, 7 and 8 contain a 5-membered ring consisting nitrogen, oxygen and sulfur heteroatoms with delocalized electrons $[18,19]$. The related mean MIC value for these compounds has been obtained $32 \mu \mathrm{g} / \mathrm{ml}$. However, in the 9 absence of delocalized electron in the molecule could be the reason of related weak MIC value. The mean MIC value for 44 samples of this group has been obtained $42.6 \mu \mathrm{g} / \mathrm{ml}$.
The compounds with two 6-membered non-fused rings: The mean MIC value for 10 consisting two fused amide groups is potent which could be probably due to the presence of delocalized electrons in the whole molecule [18-32]. The 11 shows a potent MIC value due to the presence of tertiary amine group and presence of delocalized electrons in the molecule [18]. The 10, 11 and 12 have been presented in Figure 3 so that for 12 a medium MIC value due to the presence of delocalized electrons in the molecule with four $\mathrm{OH}$ groups, which could be able to exchange the protons and essential for the antibacterial activity [28]. The mean MIC value for 62 samples of this group were obtained $20.9 \mu \mathrm{g} / \mathrm{ml}$ which was considered as a medium MIC value. 
<smiles>[R]Oc1ccc(/C=C/C(=O)NNC(=O)c2ccncc2)cc1</smiles>

10<smiles>O=C(N/N=C/Nc1ccccc1)c1ccncc1</smiles>

11<smiles>OC(C/C=C/c1ccc(Br)cc1)C(O)C(O)C(O)C/N=C/c1cccc(Br)c1</smiles>

12

Figure 3: The chemical structures of two 6-membered cyclic compounds belonging to group 4.2.

\section{The Compounds with Two Fused Rings}

The compounds with two 5-membered fused rings: The 13 consist of two 5-membered rings which are fused together by two carbon atoms. The mean MIC value for seven samples of this group has been obtained $20.5 \mu \mathrm{g} / \mathrm{ml}$ and could be due to the absence of conjugated systems [33].

The compounds with 5 and 6-membered fused rings: This group presents a potent MIC value which could be due to the presence of tertiary amine and carbonyl functional groups in the chemical structure such as thiosemicarbazone derivatives [34]. The mean MIC value for 60 samples of this group has been obtained $9.4 \mu \mathrm{g} / \mathrm{ml}$.

The compounds with two 6-membered fused rings: In this group, the structures have been presented in Figure 4 so that the 14 shows a better MIC value due to the presence of delocalized electrons in the whole molecule [35-37]. The mean MIC values for 66 samples of this group have been obtained $43.4 \mu \mathrm{g} / \mathrm{ml}$ which was considered as a medium MIC value.

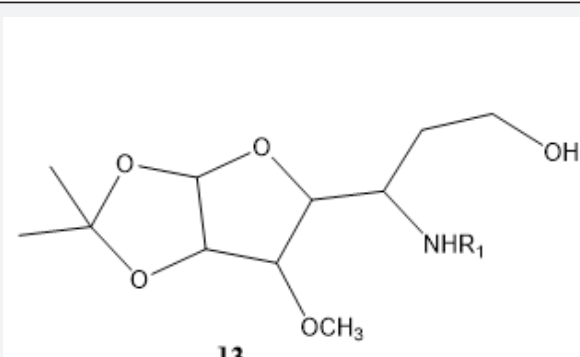

13<smiles>[R]c1ccc2c(c1)[n+]([O-])c(C)c(C(C)=O)[n+]2[O-]</smiles>

14

Figure 4: The chemical structures of fused heterocyclic compounds belonging to group 5 .

\section{The Compounds with Three Non-Fused Rings}

The compounds with three 5 and 6-membered non-fused rings: All the compounds in this group contain two phenyl groups and a 5-membered ring which is different in type and numbers of heteroatoms. The mean MIC value for 49 samples of this group has been obtained $33.5 \mu \mathrm{g} / \mathrm{ml}$ which was considered in the medium range $[38,39]$.<smiles>[R6]c1nc([R6])nc(Nc2nc([Si])cc(-c3cc([R])c(OC)c(OC)c3)n2)n1</smiles>

15<smiles>CC(C)CCN(C(=O)c1ccncc1)C(C(=O)NCc1cccnc1)c1ccccc1</smiles>

16<smiles>[R]c1ccc(-c2cc(-c3ccccn3)nn2C(=O)c2ccncc2)cc1</smiles>

Figure 5: The chemical structures of non-fused heterocyclic compounds belonging to group 6 . 
The compounds with three 6-membered non-fused rings: The compounds of this group contain three non-fused rings [40-43]. The 15 which has been presented in Figure 5, shows a medium MIC value probably due to the presence of electron donating groups such as methoxy $\left(\mathrm{OCH}_{3}\right)$ group and decreases related MIC [31]. In the 16 due to the presence of two amide groups and conjugated systems in the molecule could be changed MIC value to $7.66 \mu \mathrm{g} / \mathrm{ml}$. The mean MIC value for 32 samples of this group has been obtained $14.9 \mu \mathrm{g} / \mathrm{ml}$ which was considered as a medium MIC value.

\section{The Compounds with Three Fused Rings}

The compounds with two 5 and 6-membered fused and one 6-membered non-fused rings: These compounds consist of three rings and one of them is non-fused ring [18]. The mean MIC value for 18 samples of this group has been obtained $76.8 \mu \mathrm{g} / \mathrm{ml}$ which was in the weak range of MIC value [44-46].

The compounds with two 6-membered fused and one 6-membered non-fused rings: The mean MIC value for 54 chemical compounds of this group has been calculated for $7.1 \mu \mathrm{g} / \mathrm{ml}$ $[47,48]$.

\section{The Compounds with Four Rings}

The compounds with four non-fused rings: The chemical structures of 17 present a very potent MIC value due to the presence of conjugated systems and heteroatoms in non-fused rings
$[49,50]$. The mean MIC value for 23 samples of this group has been obtained $0.06 \mu \mathrm{g} / \mathrm{ml}$.

The compounds with two non-fused and two fused rings: The mean MIC value for 52 samples of this group has been obtained $24.4 \mu \mathrm{g} / \mathrm{ml}$ [47-52].

The compounds with two set of two fused rings: The 18 shows a very potent MIC value due to the presence of conjugated systems in the molecule and also the presence of amide group and carbonyl group in the chemical structure [53]. The mean MIC value for five samples of this group has been obtained $0.4 \mu \mathrm{g} / \mathrm{ml}$.

The compounds with three fused and one non-fused rings: The mean MIC value for 19 samples of this group has been obtained $81.6 \mu \mathrm{g} / \mathrm{ml}$ which was in the medium range $[17,54]$.

\section{The compounds with four fused rings}

The mean MIC value for 18 samples of this group has been obtained $34.3 \mu \mathrm{g} / \mathrm{ml}$ [55].

\section{The Compounds with Five Rings}

The compounds with four fused and one non-fused rings: The 19 shows a very potent MIC value due to the presence of conjugated systems in the molecule which has been presented in Figure 6 and also have an electronegative atom such as bromine $(\mathrm{Br})$ in the chemical structure. The mean MIC value for 17 samples of this group has been obtained $0.003 \mu \mathrm{g} / \mathrm{ml}$ [56].
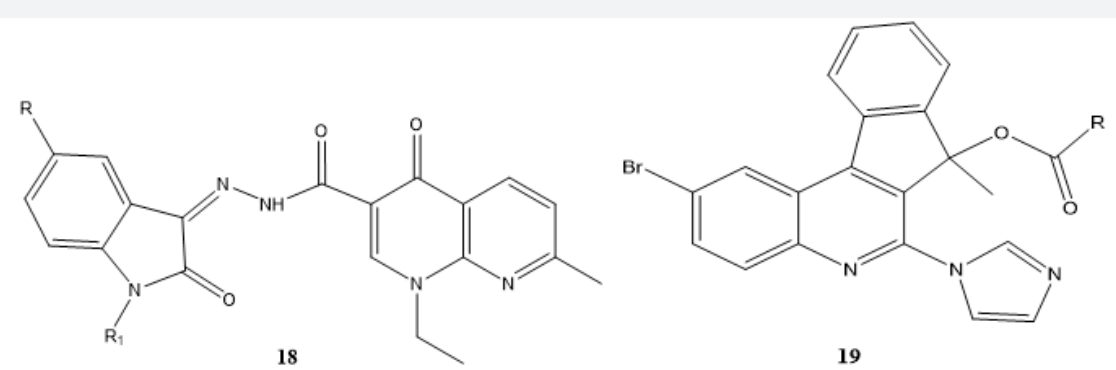

Figure 6: The chemical structures of fused heterocyclic compounds belonging to groups 8 and 9 .

The compounds with three fused and two non-fused rings: The mean MIC value for 19 samples of this group has been obtained $81.6 \mu \mathrm{g} / \mathrm{ml}[17,57]$.

\section{The Compounds with Six Rings}

The mean MIC value for 24 samples of this group has been obtained $0.24 \mu \mathrm{g} / \mathrm{ml}[47,58,59]$.

\section{The Compounds with Seven Rings}

These synthetic seven cyclic compounds contain fewer number of fused and non-fused rings compared to the other compounds in this study. The mean MIC value has been obtained $99.8 \mu \mathrm{g} / \mathrm{ml}$ which was considered as weak MIC value [56- 66].

\section{Chemistry}

Along with comparing different chemical structure of the heterocyclic organic compounds with related MIC data, an algorithm containing the ring numbers and fused or non-fused rings was considered. Some chemical properties such as presence of delocalized electrons in the whole molecule, number of heteroatoms in the heterocyclic organic compounds and also the presence of electronegative substitutions in the compounds were found which affect antibacterial activities of these compounds. These chemical properties could be helped medicinal chemists to synthesize novel chemical compounds with better predicted characteristics and more antibacterial activities of drugs.

\section{Pharmacology}

Among the mentioned chemical compounds, the 19 with four fused and one non-fused rings have all characteristics which has been found to affect the potency against Mycobacterium and has presented very potent MIC value. The toxicity for this compound was shown a selectivity index higher than 4 , therefore the 19 could be considered as potential candidate as well. 


\section{Novel Approaches in Drug Designing \& Development}

\section{Conclusion}

In this study, it has been tried to find a significant relationship between the MIC values of the heterocyclic organic compounds and their chemical structures. The most significant factor to improve the MIC values has been observed to be the presence of delocalized electrons in the whole structure of the compound $[9,24,25,51]$. The second important factor to improve the MIC values has been found to be the presence of electronegative substitutions such as bromine which would lead to a better potential MIC values in the mentioned groups $[17,23,53]$. The third factor affect the MIC values has been shown the presence of heteroatom such as nitrogen and sulfur in the rings of the heterocyclic compounds. Also the presence of fused rings in the compounds leads to a better MIC values [21,34,51]. Among the 100 evaluated compounds in this study, 17 and 19 were found to be the most active compound with MIC of 0.06 and $0.003 \mu \mathrm{g} / \mathrm{ml}$ against Mycobacterium, respectively. The presence of amide and tertiary amine groups could improve the MIC values in addition to the factors mentioned [61-66]. Although, this study reviews the effects of chemical structure on potency of these heterocyclic compounds that present Antimycobacterial effects to give idea for future therapeutic approaches.

\section{Declaration of Interest}

The authors declare no conflict of interest.

\section{References}

1. Cole ST, Alzari PM (2007) Towards new tuberculosis drugs. Journal of biochemical society transactions 35(5): 1321-1324.

2. Johnson R (2006) Drug resistance in Mycobacterium tuberculosis. Current issues in molecular biology 8(2): 97-111.

3. Khaled NA, Enarson DA (2003) Tuberculosis a manual for medical students. World Health Organization.

4. Perry TL, Wright JM, Hansen S (1982) A double-blind clinical trial of isoniazid in Huntington disease. Neurology 32(4): 354-358.

5. Baggenstoss AH, Feldman WH, Hinshaw HC (1947) Streptomycin in miliary tuberculosis; its effect on the pathological lesions of generalized miliary tuberculosis in human beings. Am Rev Tuberc 55(1): 54-76.

6. Chadha VK (2009) Progress towards millennium development goals for TB control in seven Asian countries. Indian Journal of Tuberculosis 56: $30-43$

7. Kaye K, Frieden TR (1996) Tuberculosis control: the relevance of classic principles in an era of acquired immunodeficiency syndrome and multidrug resistance. Epidemiol Rev 18(1): 52-63.

8. Kochi A (1991) The global tuberculosis situation and the new control strategy of the World Health Organization. Tubercle 72(1): 1-6.

9. World Health Organization (2009) Global tuberculosis control: epidemiology, strategy, financing. WHO report 303.

10. Krystyna IW, Grudniak AM, Fiecek B (2010) Antibacterial activity of oleanolic and ursolic acids and their derivatives. Central European Journal of Biology 5(5): 543-553.

11. Daryaee F, Kobarfard F, Khalaj A, Farnia P (2009) Synthesis and evaluation of in vitro anti-tuberculosis activity of N-substituted glycolamides. Eur J Med Chem 44(1): 289-295.

12. Montes D'Oca CDR, Coelho T, Marinho TG (2010) Synthesis and antituberculosis activity of new fatty acid amides. Bioorg Med Chem Lett 20(17): 5255-5257.

13. Olmo ED, Salina GMM, Escarcena R (2009) Simple dihydrosphyngosine analogues with potent activity against MDR-Mycobacterium tuberculosis. Bioorg Med Chem Lett 19(9): 5764-5768.

14. Azerang P, Rezayan AH, Sardari S (2012) Synthesis and biological evaluation of propargyl acetate derivatives as anti-mycobacterial agents. Journal of pharmaceutical sciences 20: 90.

15. Janin YL (2007) Antituberculosis drugs: ten years of research. Bioorg Med Chem 15(7): 2479-2513.

16. Davis CB (2007) Synthesis and biological evaluation of galactofuranosyl alkyl thioglycosides as inhibitors of mycobacteria. Carbohydr Res 342(12-13): 1773-1780.

17. De P, Yoya GK, Consant P (2011) Design, synthesis, and biological evaluation of new cinnamic derivatives as antituberculosis agents. J Med Chem 54(5): 1449-1461.

18. Huang Q, Mao J, Wan B (2009) Searching for new cures for tuberculosis: Design, synthesis, and biological evaluation of 2-Methylbenzothiazoles. Journal of medicinal chemistry 52: 6757-6767.

19. EbrahimTehrani KHM, Sardari S, Mashayekhi V (2013) One pot synthesis and biological activity evaluation of novel schiff bases derived from 2-Hydrazinyl-1,3,4-thiadiazole. Chem Pharm Bull 61(2):160-166.

20. Zitko J, Dolezal M, Svobodova M (2011) Synthesis and antimycobacterial properties of N-substituted 6-amino-5-cyanopyrazine-2carboxamides. Bioorganic and medicinal chemistry 19: 1471-1476.

21. Zitko J, Jampilek J, Dobrovolny L (2012) Synthesis and antimycobacterial evaluation of $\mathrm{N}$-substituted 3-aminopyrazine-2,5-dicarbonitriles. Bioorg Med Chem Lett 22: 1598-1601.

22. Zanze IA (2008) Isocyanide-based multicomponent reactions in drug discovery. Curr Opin Chem Biol 12(3): 324-331.

23. Domling A, Achatz S, Beck B (2007) Novel anti-tuberculosis agents from MCR libraries. Bioorganic and medicinal chemistry letters 17(19): 5483-5486.

24. Sriram D, Yogeeswari P, Methuku S (2011) Synthesis of various 3-nitropropionamides as Mycobacterium tuberculosis isocitratelyase inhibitor. Bioorganic and medicinal chemistry letters 21: 5149-5154.

25. Krátký M, Vinsova J, Volkova M (2012) Antimicrobial activity of sulfonamides containing 5-chloro-2-hydroxybenzaldehyde and 5-chloro-2-hydroxybenzoic acid scaffold. Eur J Med Chem 50: 433-440.

26. Castagnolo D, De Logu A, Radi M, Bechi B, Manetti F, et al. (2009) Synthesis, biological evaluation, and SAR study of novel pyrazole analogues as inhibitors of Mycobacterium tuberculosis. Bioorg Med Chem 17: 5716-5721.

27. Lee SH, Suhyun Yun, Min-Han Lee, Yong Sup, et al. (2011) Synthesis and antitubercular activity of monocyclic nitroimidazoles: Insights from econazole. Bioorganic and medicinal chemistry letters 21: 1515-1518.

28. Shanmugavelan, Poovan Nagarajan, Sangaraiah Sathishkumar, Murugan Ponnuswamy, Alagusundaram (2011) Efficient synthesis and in vitro antitubercular activity of 1,2,3-triazoles as inhibitors of Mycobacterium tuberculosis. Bioorganic and medicinal chemistry letters 21: 7273-7276.

29. A Lilienkampf, M Pieroni, B Wan (2010) Rational design of 5-Phenyl3-isoxazolecarboxylic acid ethyl esters as growth inhibitors of Mycobacterium tuberculosis, a potent and selective series for further drug development. J Med Chem 53(2): 678-688.

30. Vavríková E, Polanc S, Kocevaret M (2011) New series of isoniazid hydrazones linked with electron-withdrawing substituent. Eur J Med Chem 46(12): 5902-5909. 


\section{Novel Approaches in Drug Designing \& Development}

31. Sunduru N, Gupta L, Chaturvedi V (2010) Discovery of new 1,3,5-triazine scaffolds with potent activity against Mycobacterium tuberculosis. Eur J Med Chem 45(8): 3335-3345.

32. Ferreira MDL, Vasconcelos TRA, Carvalho EMD (2009) Synthesis and antitubercular activity of novel schiff bases derived from D-mannitol. Carbohydrate research 344(15): 2042-2047.

33. Katiyar D, Tiwari VK, Tewari N (2005) Synthesis and antimycobacterial activities of glycosylated amino alcohols and amines. European journal of medicinal chemistry 40(4): 351-360.

34. Banerjee D, Yogeeswari P, Bhat P (2011) Novel isatinyl thiosemicarbazones derivatives as potential molecule to combat HIVTB co-infection. European journal of medicinal chemistry 46(1):106 121

35. Villar R, Vicente E, Solano B (2008) In vitro and in vivo antimycobacterial activities of ketone and amide derivatives of quinoxaline 1,4-di-Noxide. J Antimicrob Chemother 62(3): 547-554.

36. Meseguer JP, Olmo ED, Garza BA (2012) Synthesis of leubethanol derivatives and evaluation against Mycobacterium tuberculosis Bioorganic and medicinal chemistry 20(13): 4155-4163.

37. Rezayan AH, Azerang P, Sardari S, Sarvary A (2012) Synthesis and biological evaluation of coumarin derivatives as inhibitors of Mycobacterium bovis. Chem Biol Drug Des 80(6): 929-936.

38. Doležal M, Zitko J, Kešetovičová D, Kuneš J, Svobodová M (2009) Substituted N-phenylpyrazine-2-carboxamides: Synthesis and antimycobacterial evaluation. Molecules 14(10): 4180-4189.

39. Castagnolo D, Logu AD, Radi M (2008) Synthesis, biological evaluation and SAR study of novel pyrazole analogues as inhibitors of Mycobacterium tuberculosis. Bioorg Med Chem 16(18): 8587-8591.

40. Tangallapally RP, Yendapally R, Lee ER, Lenaerts AJM, Lee RE (2008) Synthesis and evaluation of cyclic secondary amine substituted phenyl and benzyl nitrofuranyl amides as novel antituberculosis agents Journal of medicinal chemistry 48: 8261-8269.

41. Krátký M, Vinšová J, Rodriguez NG, Stolaříková J (2012) Antimycobacterial activity of salicylanilide benzene sulfonates Molecules 17(1): 492-503.

42. Ali MA, Samy JG, Manogaran E (2009) Synthesis and antimycobacterial evaluation of novel 5,6-dimethoxy-1-oxo-2,5-dihydro-1H-2-indenyl-5, 4-substituted phenyl methanone analogues. Bioorg Med Chem Lett 19(24): 7000-7002.

43. Tehrani KHM, Mashayekhi V, Azerang P (2014) Synthesis and antimycobacterial activity of novel thiadiazolyl hydrazones of 1-substituted indole-3-carboxaldehydes. Chem Biol Drug Des 83(2) 224-236.

44. Kakwani MD, Desai NHP, Lele AC (2011) Synthesis and preliminary biological evaluation of novel N-(3-aryl-1,2,4-triazol-5-yl) cinnamamide derivatives as potential antimycobacterial agents: An operational topliss tree approach. Bioorg Med Chem 21(21): 65236526.

45. Santos JL, Yamasaki PR, Chin CM (2009) Synthesis and in vitro antiMycobacterium tuberculosis activity of a series of phthalimide derivatives. Bioorg Med Chem 17(11): 3795-3799.

46. Waisser K, Gregor J, Dostal H (2001) Influence of the replacement of the oxo function with the thioxo group on the antimycobacterial activity of 3-aryl-6,8-dichloro-2H-1,3-benzoxazine-2,4(3H)-diones and 3-arylquinazoline-2,4 diones. Farmaco 56(10): 803-807.

47. Ancizu S, Elsa Moreno, Beatriz Solano, Raquel Villar, Asunción Burguete, et al. (2010) New 3-methylquinoxaline-2-carboxamide 1,4-di-N-oxide derivatives as antimycobacterium tuberculosis agents. Bioorganic and medicinal chemistry 18(7): 2713-2719.

48. Mamolo MG, Zampieri D, Falagiani V, Vio L, Banfi E (2001) Synthesis and antimycobacterial activity of 5-aryl-1-isonicotinoyl-3-(pyridin-2-
yl)-4,5-dihydro-1H-pyrazole derivatives. Farmaco 56(8): 593-599.

49. Castagnolo D, MarcoRadi, Filippo Dessì, Fabrizio Manetti, Manuela Saddi, Rita Meleddu, et al. (2009) Synthesis and biological evaluation of new enantiomerically pure azole derivatives as inhibitors of Mycobacterium tuberculosis. Bioorganic and medicinal chemistry letters 19(8): 2203-2205.

50. Banerjee D, Yogeeswari P, Bhat P, Thomas A, Sriram D (2010) Synthesis, in-vitro evaluation and computational studies of novel isatinyl derivatives for their activity against HIV-TB Co-infection. International journal of drug discovery 1(1): 65-80.

51. Sriram D, Yogeeswari P, Thirumurugan R, Pavana RK (2006) Discovery of new antitubercular oxazolyl thiosemicarbazones. J Med Chem 49(12): 3448-3450

52. Fadl TA, Bin Jubair FAS, Wafa OA (2010) Schiff bases of indoline-2,3dione (isatin) derivatives and nalidixic acid carbohydrazide, synthesis, antitubercular activity and pharmacophoric model building. Eur J Med Chem 45(10): 4578-4586.

53. Ahsan MJ, Samy GJ, Khalilullah H, Bakht MA, Hassan MZ (2011) Synthesis and antimycobacterial evaluation of 3a,4-dihydro-3Hindeno [1,2-c] pyrazole-2-carboxamide analogues. Eur J Med Chem 46(11): 5694-5697.

54. Kumar RS, Rajesh SM, Perumal S (2010) Novel three-component domino reactions of ketones, isatin and amino acids: Synthesis and discovery of antimycobacterial activity of highly functionalized novel dispiropyrrolidines. European journal of medicinal chemistry 45 411-422.

55. Upadhayaya RS, Shinde PD, Kadam SA (2011) Synthesis and antimycobacterial activity of prodrugs of indeno [2,1-c] quinoline derivatives. Eur J Med Chem 46(4): 1306-1324.

56. Ahsan MJ, Samy JG, Soni S (2011) Discovery of novel antitubercular 3a,4dihydro-3H-indeno [1,2-c] pyrazole-2-carboxamide/carbothioamide analogues. Bioorg Med Chem Lett 21(18): 5259-5261.

57. Kantevari S, Yempala T, Surineni G (2011) Synthesis and antitubercular evaluation of novel dibenzo [b,d] furan and 9-methyl-9H-carbazole derived hexahydro-2H-pyrano [3,2-c] quinolines via Povarov reaction. Eur J Med Chem 46(10): 4827-4833.

58. Upadhayaya RS, Kulkarini GM, Vasireddy NR (2009) Design, synthesis and biological evaluation of novel triazole, urea and thiourea derivatives of quinoline against Mycobacterium tuberculosis. Bioorg Med Chem 17(3): 4681-4692.

59. Onajole OK, Govender K, Govender P (2009) Pentacyclo-undecane derived cyclic tetra-amines: Synthesis and evaluation as potent antituberculosis agents. Eur J Med Chem 44: 4297-4305.

60. Mousaviehzadeh M, Sardari S (2015) Susceptibility testing of Mycobacterium frederiksbergense strains isolated from Alfalfa plants against antibacterial compounds. Open journal of medical microbiology 5: 90-96.

61. Ferdosian M, Sardari S (2013) A Novel mechanistic approach to identify new antifungal lead compounds based on amphotericin B molecular architecture. Tropical journal of pharmaceutical research 12(2): 181-188

62. Arabi Z, Sardari S (2010) An investigation into the antifungal property of Fabaceae using bioinformatics tools. Avicenna journal of medical biotechnology 2: 93-100.

63. Parang K Knaus EE, Wiebe LI, Sardari S, Daneshtalab M, et al. (1996) Synthesis and antifungal activities of myristic acid analogs. Arch Pharm 329(11): 475-482.

64. Tehrani KE, Sardari S (2015) Synthesis and antimycobacteria activity of some triazole derivatives: New route to functionalized triazolopyridazines. Iranian journal of pharmaceutical research 14(1): $59-68$ 
65. Mashayekhi V, Sardari S (2013) Synthesis, antimycobacterial and anticancer activity of novel indole-based thiosemicarbazones. Arch Pharm Res 1-13.

This work is licensed under Creative Commons Attribution 4.0 License

DOI: 10.19080/NAPDD.2018.04.555633
66. Rezayan, AH, Sardari S (2017) Synthesis of novel fluorene bisamide derivatives via Ugi reaction and evaluation their biological activity against Mycobacterium species. Iran J Pharm Res 16(2): 745-755.

\section{Your next submission with Juniper Publishers will reach you the below assets}

- Quality Editorial service

- Swift Peer Review

- Reprints availability

- E-prints Service

- Manuscript Podcast for convenient understanding

- Global attainment for your research

- Manuscript accessibility in different formats

( Pdf, E-pub, Full Text, Audio)

- Unceasing customer service

Track the below URL for one-step submission https://juniperpublishers.com/online-submission.php 